\title{
Evaluation of weld filler alloying concepts for residual stress engineering by means of Neutron and X-ray diffraction
}

\author{
Arne Kromm ${ }^{1}$, a * \\ ${ }^{1}$ BAM Federal Institute for Materials Research and Testing, Unter den Eichen 8712205 Berlin, \\ Germany \\ aarne.kromm@bam.de
}

Keywords: LTT, weld filler materials, martensite

\begin{abstract}
Novel Low Transformation Temperature (LTT-) filler materials are specially designed for controlling residual stresses by means of adjusted martensite formation already during welding. Different alloying concepts compete for maximum stress reduction. Two newly developed LTTalloys were evaluated concerning their potential for residual stress control. For this purpose residual stresses were determined in the surface and also in sub-surface areas of welded joints using X-ray diffraction and Neutron diffraction taking into account local variations of the unstrained lattice parameter.
\end{abstract}

\section{Introduction}

Low transformation temperature (LTT) alloys are a smart approach for residual stress engineering in welding. Without any post weld treatments a beneficial residual stress state for different applications is aimed for. This means mostly unwanted tensile residual stresses can be avoided. Moreover, compressive residual stresses may be generated. The mechanism behind is a martensite formation at comparably low temperatures, typically around $180^{\circ} \mathrm{C}$. The martensite formation counteracts the generation of tensile shrinkage stresses due to its volume expansion and the effect of transformation plasticity [1]-[3].

LTT alloys are still in focus of research as the residual stresses resulting from the tailored phase transformation behavior are not yet completely understood. On the other hand some practical issues concerning solidification behavior and toughness are still to be solved. Most LTT related work found in the literature is based on weld filler materials showing chromium, nickel and carbon as main alloying elements [4]. In these approaches the $\mathrm{M}_{\mathrm{s}}$-temperature is mainly controlled by the amount of nickel. Beside this alloy concept single attempts were made to substitute nickel with manganese [5]. Such alloys exhibit a comparable austenite to martensite phase transformation behavior. The $\mathrm{M}_{\mathrm{s}}$-temperature can be varied similarly by the amount of manganese.

Results published regarding residual stresses in LTT joints give evidence about the existence of compressive residual stresses, especially when the material volume was evaluated [6]-[9]. Own investigations revealed that LTT welds may also show tensile residual stresses when the focus was put on the surface of the joints [10]. Especially near surface residual stress measurements in LTT joints are neglected in the literature. Therefore, any evaluation should incorporate the surface as well as the bulk material whenever possible. Within the present work two different LTT alloys are compared regarding the residual stresses in the surface and the material volume. For this purpose conventional X-ray diffraction (XRD) and Neutron diffraction (ND) were applied.

\section{Experimental}

Materials and welding. Based on already published chemical compositions two experimental LTT alloys were prepared. Some characteristics are presented in Table 1. Both LTT materials show the main alloying elements chromium and nickel, respectively manganese. For reasons of weldability the carbon contents were kept below $0.1 \%$. The $\mathrm{M}_{\mathrm{s}}$-temperatures show a difference of about $100 \mathrm{~K}$. The materials were welded in form of flux-cored wires using MAG-process. Butt welds showing an opening angle of $60^{\circ}$ were prepared according to Fig. 1. Joining was performed manually ( 160 A- 
$180 \mathrm{~A}, \sim 25 \mathrm{~V})$ in multi-run welding without any preheating in nine runs. As base material the high strength low alloyed steel S960QL (1.8933) according to EN 10025 in quenched and tempered condition was chosen in a thickness of $15 \mathrm{~mm}$.

Table 1: Characteristics of the LTT alloys and base material

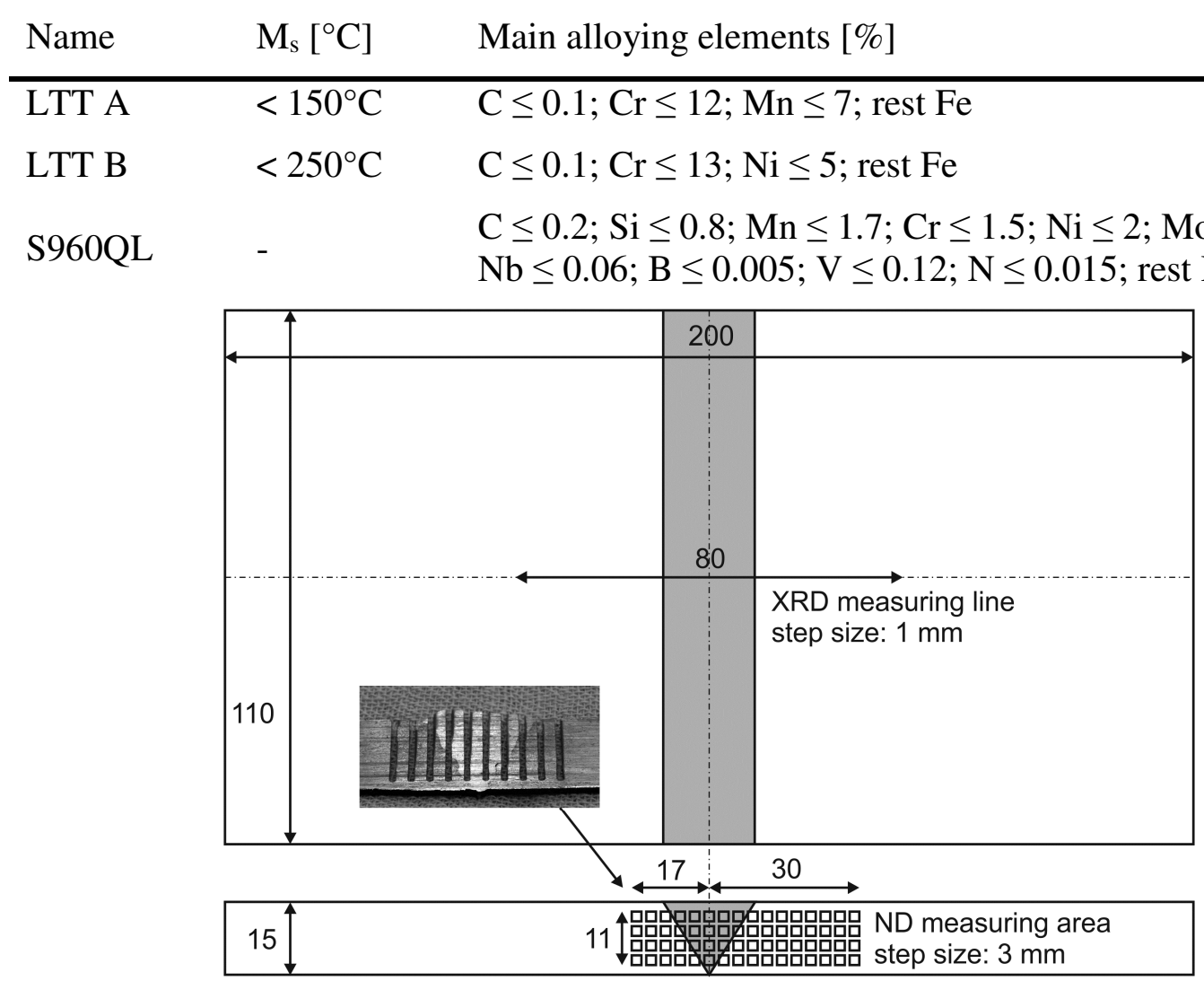

Figure 1: Schematic of the sample showing the measurement positions for X-ray (XRD) and Neutron diffraction (ND) as well as the reference specimen.

X-ray stress measurement. The residual stresses were measured on the top surface of the samples using the well-known $\sin ^{2} \psi$ technique [11]. The measurement points were situated at half of the weld length according to Fig. 1. While in the weld and heat affected zone a step size of $1 \mathrm{~mm}$ was chosen the base material was measured in $5 \mathrm{~mm}$ steps. Longitudinal as well as transverse residual stresses were determined using the parameters shown in Table 2.

Table 2: X-ray measuring and evaluation parameters

\begin{tabular}{l|l} 
Radiation & $\mathrm{CrK}_{\alpha}$ \\
Lattice plane $\{\mathrm{hkl}\}$ & Ferrite: 211 \\
Aperture $[\mathrm{mm}]$ & 2 \\
Exposure time $[\mathrm{s}]$ & 5 \\
$\mathrm{E}\{211\}[\mathrm{MPa}]$ & 220.000 \\
$\nu\{211\}$ & 0.28 \\
$\psi$ range & $-45^{\circ}$ to $45^{\circ}(7$ to 10 steps $)$
\end{tabular}

Neutron stress measurement. Diffraction experiments were performed at the E3 beamline at the BERII facility of HZB in Berlin, Germany. As a multi-axial stress state was to be expected in the welded joints, strain measurement was necessary in three independent directions covering the 
longitudinal, transverse and weld depth direction. Using a neutron wavelength of $\sim 1.486 \AA$ the $\alpha$ Fe $\{211\}$ diffraction peak located at approximately $2 \Theta=78^{\circ}$ was utilized for strain measurement. The exposure time varied between $10 \mathrm{~min}$ to $20 \mathrm{~min}$. From the strains in three individual directions the stresses can be calculated. A gauge volume of $\sim 2 \cdot 2 \cdot 2 \mathrm{~m}^{3}$, adjusted by primary slits and a radial collimator, was chosen in order to have sufficient spatial resolution. To achieve an acceptable compromise of spatial resolution and measured sample size the measuring positions were realized as shown in Fig. 1. Four measuring lines in distances of 3, 6, 9 and $12 \mathrm{~mm}$ to the plate surface were chosen. The measuring range included the weld and both sides of the heat affected zone while the base material was covered only single sided. As the LTT weld metals are higher alloyed compared to the base material the unstrained lattice parameter a 0 was determined from appropriate reference specimens. For this purpose a thin comb was cut from each sample representing the weld cross section including the heat affected zone and the base material. The prongs of the comb were prepared using water jet cutting in order to avoid any thermal effects on the material. The unstrained lattice parameters are shown in Fig. 2. Additionally, the full width half maximum (FWHM) measured on the plate surfaces by X-ray diffraction is included. It becomes clear, that the determination of $\mathrm{a}_{0}$ is crucial for reliable statements about residual stresses in high alloyed welds. The lattice parameter shows a gradient within the weld metal at which LTT A is affected more compared to LTT B as already indicated by the FWHM on the top surface.
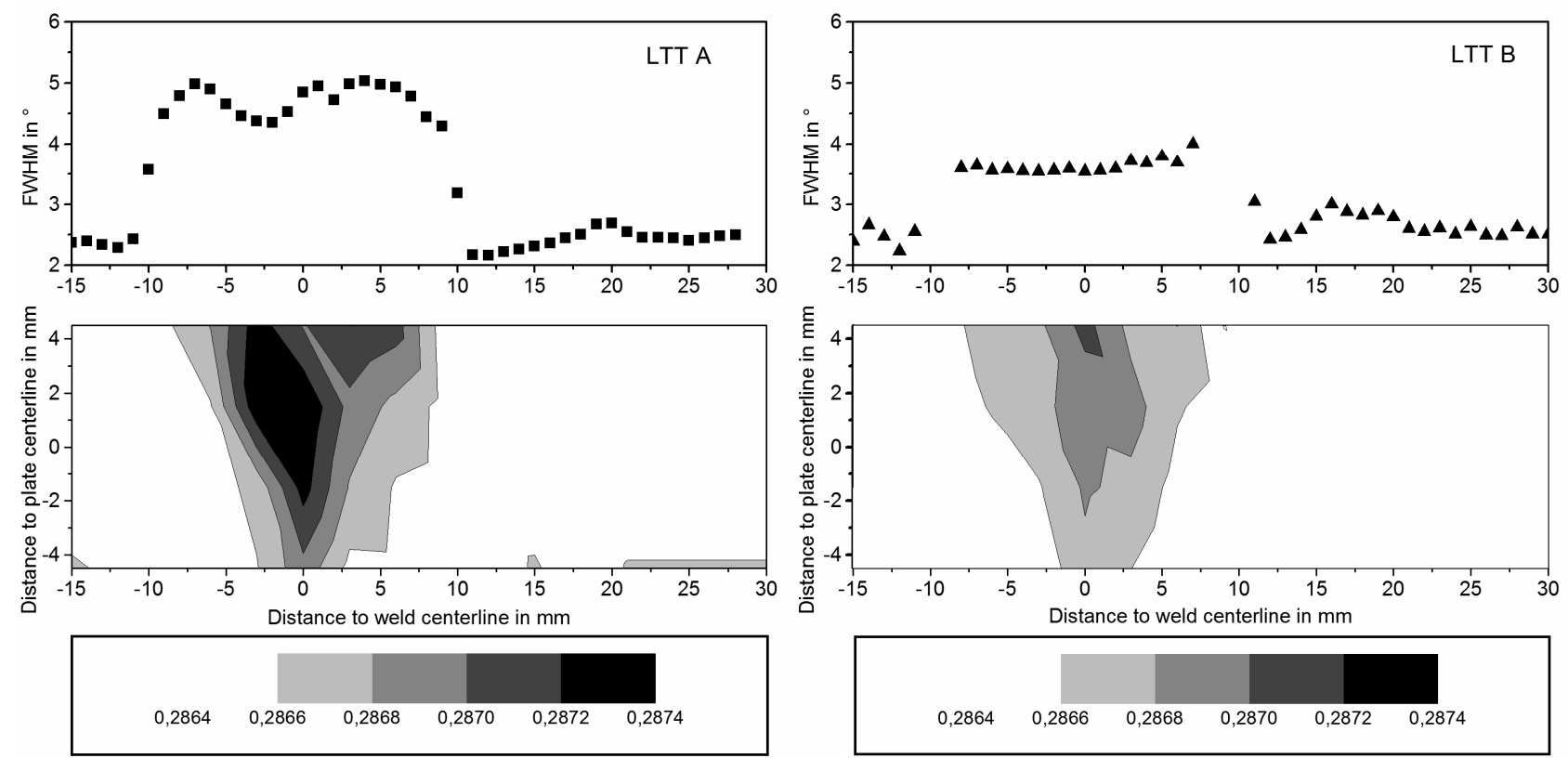

Figure 2: FWHM at the surface (top) and unstrained lattice parameter a in $\mathrm{nm}$ (bottom) obtained for the joints LTT A (left) and LTT B (right)

\section{Results}

Residual Stresses - Surface. Residual stresses found near the surface of both welds are presented in Fig. 3. It is obvious, that the longitudinal residual stress distribution of the joints is quite similar in quality. Moreover, the residual stress level in the welds is almost identical. Solely the weld center is somewhat differing. The weld is characterized mainly by compressive residual stresses of up to $-375 \mathrm{MPa}$ particular adjacent to the heat affected zone. The transition to the heat affected zone shows a steep residual stress gradient. Therefore, this area is characterized by the highest tensile residual stresses of about $250 \mathrm{MPa}$. These tensile residual stress peaks are typical for transformation affected welds. Adjacent to the heat affected zone the residual stresses decrease to rather low levels. Slight differences are to be found between the joints here, as the residual stress level of LTT A is lower in selected points than LTT B, which may be attributed to manual welding. This applies also for the transverse direction. The heat affected zone shows residual stress levels up to $-465 \mathrm{MPa}$ 
here. Beside some single stress peaks the residual stress distribution in the weld is quite similar between both LTT joints, as already observed for the longitudinal direction. While the longitudinal direction is characterized by compression in the weld the transverse direction shows a diverse residual stress distribution. Tensile as well as compressive residual stresses from approximately the same magnitude are present. Taking into account that welding was performed manually the almost identical residual stress characteristics - despite different alloying concepts and varying $\mathrm{M}_{\mathrm{s}^{-}}$ temperatures - may surprise. However, the results are in good correlation with former findings of the author and coworkers about surface residual stresses in LTT welds [10].
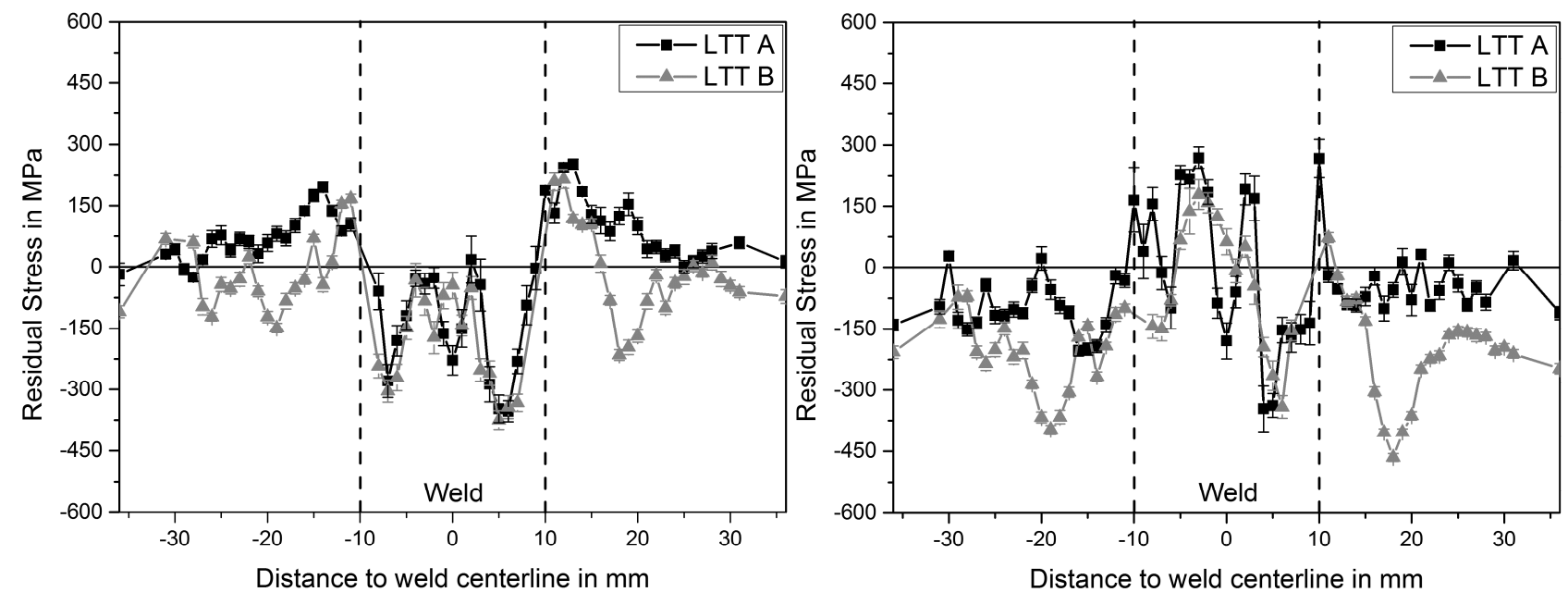

Figure 3: Surface residual stress distribution for LTT A and LTT B in longitudinal (left) and transverse direction (right)

Residual Stresses - Volume. Longitudinal residual stresses found in the material volume are shown in Fig. 4 (left) for both LTT weld metals. Compressive residual stresses are mainly concentrated in the upper part of the weld, whereas the lower part is characterized by balancing tensile residual stresses. The highest compressive residual stresses registered are around -600 MPa (LTT A), respectively $-670 \mathrm{MPa}$ (LTT B). The high stress gradients found on the surface in the transition from the weld to the heat affected zone are also present in deeper layers. According to the $\mathrm{V}$-shape of the joint the weld metals are surrounded by tensile residual stresses up to $870 \mathrm{MPa}$ according to the strength of the base material. Contrary to the compressive residual stresses located mainly in the upper part of the weld metal, the tensile residual stresses of the heat affected zone are distributed almost equally adjacent to the weld including deeper layers, too. As stated already for the surface residual stress distribution, the residual stresses in the bulk material are quite similar in quality as well as quantity for both LTT joints despite single points showing deviant behavior. The observation that the absolute compressive residual stress level is increased in subsurface areas compared to the surface is conform to already published data [6], [10].

Residual stresses normal to the plate top surface are shown in Fig. 4 (right). Note, that the residual stresses found in transverse direction are similar in quality but less in quantity and therefore are not shown. Within the weld area compressive as well as tensile residual stresses are present. Compressive residual stresses are mainly located in the upper part of the weld, similar to the longitudinal direction. The maximum residual stress level yields just about -320 MPa (LTT A) and -450 MPa (LTT B). Lower amounts of compressive residual stresses in normal/transverse direction compared to longitudinal direction were reported also in [6]-[9]. The heat affected zone shows the highest residual stress levels situated rather in the upper part of the joint. Solely tensile residual stresses exceeding $700 \mathrm{MPa}$ are present. According to longitudinal direction single tensile stress peaks may be present in the weld metal as observed for LTT A in a depth of $-6 \mathrm{~mm}$ from the top surface. 
It is remarkable, that the residual stress peaks found in the bulk material are significant higher than residual stresses determined near the surface of the samples. This applies for the compressive residual stresses in the weld as well as for the tensile ones in the heat affected zone. The threedimensional stress state present in the material volume may responsible for that observation as the higher degree of restraint related to that give rise to higher residual stresses. Also a delayed martensite transformation due to temperature gradients across the volume which undergoes martensite formation may contribute to diverse residual stresses over the weld cross section. It follows, that especially for multilayer welds on corresponding plate thicknesses, surface and volume need to be considered separately to allow for reliable statements about the level of residual stresses in LTT-welds.

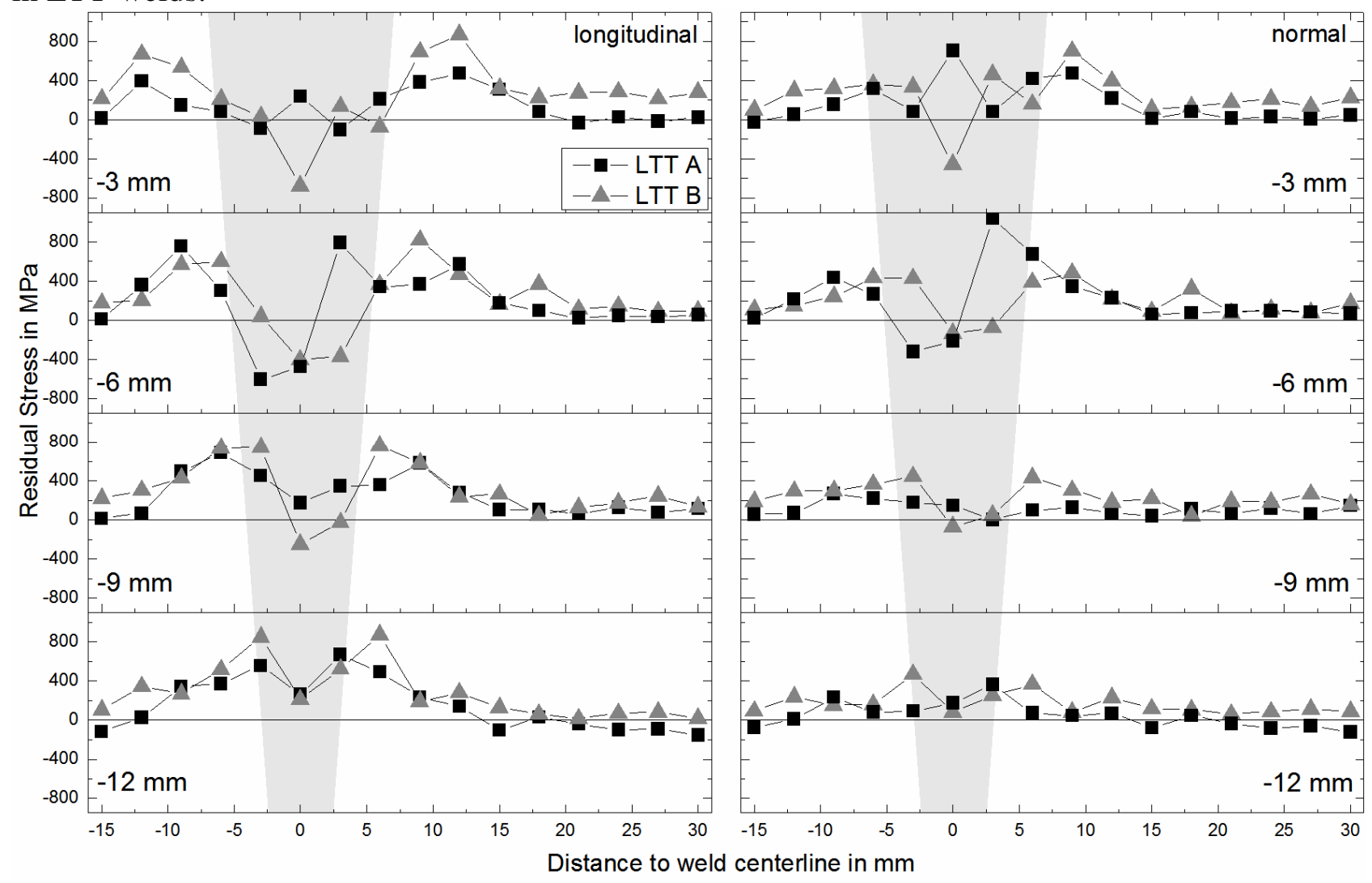

Figure 4: Longitudinal residual stresses (left) and normal residual stresses (right) for LTT A and LTT B in varying distances to the top surface measured by ND, weld area indicated grey

\section{Summary and Conclusions}

The present work dealt with the residual stresses as a result of welding a high strength base material with two different LTT filler wires. The residual stresses were determined separately on the joints surface using conventional X-ray diffraction as well as in the bulk material applying Neutron diffraction. From this study, the following conclusions can be drawn. Despite different main alloying elements and therefore different $\mathrm{M}_{\mathrm{s}}$-temperatures the residual stresses found near the surface as well as in deeper layers of the welds are quite similar. This applies on the one hand for the residual stress distributions, especially in weld longitudinal direction. On the other hand the compressive residual stresses present in both welds are approximately from the same magnitude between -600 MPa and -700 MPa. On the other hand balancing high tensile residual stresses are observed for the adjacent heat affected zone which may reach the yield point of the base material. The results are in good correlation with literature data concerning residual stresses in LTT welded joints [6]-[9]. Both alloys used within this study are appropriate to generate compressive residual stresses in the weld metal. Nevertheless, balancing tensile residual stresses are not negligible. Therefore, systematic evaluation of the influence of boundary conditions (welding parameters, joint configuration) is necessary and scheduled to future investigations. 


\section{Acknowledgements}

This work is funded by DFG (German Research Foundation, KR 3917/1-1). The author would like to acknowledge HZB for granting beamtime at BERII and Mirko Boin and Robert Wimpory for their excellent support at the E3 beamline. Special thanks goes to Lincoln Electric Europe for providing the LTT filler wires.

\section{References}

[1] H. Wohlfahrt, E. Macherauch, Die Ursachen des Schweißeigenspannungszustandes. Materialprüfung 19 (1977) 272-280. (In German)

[2] T, Nitschke-Pagel, H. Wohlfahrt, Residual Stresses in Welded Joints - Sources and Consequences, Mater. Sci. Forum 404-407 (2002) 215-226.

[3] H.K.D.H. Bhadeshia, Developments in Martensitic and Bainitic Steels: Role of the Shape Deformation, Mater. Sci. Eng. A378 (2004) 34-39.

[4] A. Ohta, O. Watanabe, K. Matsuoka, C. Shiga, S. Nishijima, Y. Maeda, N. Suzuki, T. Kubo, Fatigue Strength improvement by using newly developed low transformation temperature welding material, Welding in the World 43 (1999) 38-42.

[5] F. Martinez Diez, Development of Compressive Residual Stress in Structural Steel Weld Toes by Means of Weld Metal Phase Transformations, Welding in the World 52 (2008) 63-78.

[6] J. Gibmeier, E. Obelode, J. Altenkirch, A. Kromm, T. Kannengiesser, Residual stress in steel fusion welds joined using low transformation temperature (LTT) filler material, Mater. Sci. Forum 768-769 (2014) 620-627.

[7] C. Shiga, H.Y. Yasuda, K. Hiraoka, H. Suzuki, Effect of Ms temperature on residual stress in welded joints of high- strength steels, Welding in the World 54 (2010) 71-79.

[8] D. Thibault, P. Bocher, M. Thomas, M. Gharghouric, M. Côté, Residual stress characterization in low transformation temperature $13 \% \mathrm{Cr}-4 \% \mathrm{Ni}$ stainless steel weld by neutron diffraction and the contour method, Mater. Sci. Eng. A527 (2010) 6205-6210.

[9] R.J. Moat, H.J. Stone, A.A. Shirzadi, J.A. Francis, S. Kundu, A.F. Mark, H.K.D.H. Bhadeshia, L. Karlsson, P.J. Withers, Design of weld fillers for mitigation of residual stresses in ferritic and austenitic steel welds, Sci. Technol. Weld. Joi. 16 (2011) 279-284.

[10]A. Kromm, T. Kannengiesser, J. Altenkirch, J. Gibmeier, Residual Stresses in Multilayer Welds with Different Martensitic Transformation Temperatures Analyzed by High-Energy Synchrotron Diffraction. Mater. Sci. Forum 681 (2011) 37-42.

[11]E. Macherauch, P. Müller, Das $\sin ^{2} \psi$-Verfahren der röntgenographischen Spannungsmessung, Zeitschrift für angewandte Physik 13 (1961) 305-312. (in German) 